\title{
Equatorial|
}

Dossiê: Etnografando experiências do adoecimento e medicalização no Brasil

\section{Como as doenças compridas podem nos ensinar sobre os serviços de saúde?}

Soraya Fleischer

Professora do Departamento de Antropologia

Universidade de Brasília

fleischer.soraya@gmail.com

\section{RESUMO}

Recentemente, em um muro diante de minha casa, foi deixada uma mensagem na calada da noite. Em letras vermelhas, lia-se "Vandalismo é a fila do SUS". Inspirada por essa eloquente mensagem, decidi priorizar, para esse artigo, o que eu tenho ouvido de meus interlocutores ao enfrentarem as filas e desafios do SUS. Esse artigo pretende mostrar como é doloroso sentir esse tipo de vandalismo na própria pele todos os dias, somado às dores provocadas pelas doenças compridas, como tenho ouvido na Guariroba, bairro histórico da Ceilândia/DF, ao me informar sobreas doenças ditas crônicas. Pretendo adensar as percepções sobre o funcionamento das instituições de saúde locais. Para tanto, trago três sentidos que emergem com força entre nossos dados: O "esperar" pelos serviços de saúde, o "ser atendido/a" pelos mesmos e, por fim, o "correr atrás" individualmente e/ou coletivamente de soluções para suplantar as limitações encontradas nesses serviços. Algo mais específico é acumulado pela experiência do adoecimento prolongado para melhor enfrentar o vandalismo diário realizado pelo SUS.

Palavras-chave: Cronicidade; Serviços de saúde; Atenção básica.

\section{Introdução: as doenças compridas}

A literatura epidemiológica tem preferido adjetivar como "crônico" o sofrimento ou padecimento que não tem cura definitiva e tende ao que tem sido chamado como "degeneração", necessitando, muitas vezes, de "cuidados paliativos" ao final da vida. Essa definição se desenha em contraste com os padecimentos "agudos" que, repetidamente, podem ser transmissíveis, contagiosos e fatais (Parsons, 1971). Mas as fronteiras se borram com mais frequência do que o previsto para essa nomenclatura e é possível encontrar doenças agudas que depois se cronificam, como a Doença de Chagas ou mesmo a AIDS, por exemplo; 
ou doenças crônicas que, mesmo assintomáticas em alguns casos, podem ter períodos de sérias crises, como acontece com pessoas com hipertensão arterial que sofrem derrames e acidentes vasculares cerebrais ou no caso da Doença Pulmonar Obstrutiva Crônica, quando falta oxigênio ou há sincopes repentinas. Além disso, dada a sua permanência e a discrição sintomática, essas patologias definidas como crônicas talvez sequer sejam percebidas como "doenças". Essas são algumas das críticas que colegas da Antropologia têm feito e, por isso, têm preferido adotar, por exemplo, a ideia de "doença de longa duração" (Canesqui, 2007).

Em concordância com essa crítica, começo a ensaiar o uso de um terceiro termo, que surgiu em nossa pesquisa no bairro da Guariroba, na cidade de Ceilândia/DF. Dona Marieta era uma senhora piauiense com mais de 60 anos que, há uma década, cuidava do marido, Seu Josenildo, doente de hipertensão e bastante abatido por uma sucessão de derrames. Quando ela se referia à doença do marido, geralmente dizia "eu cuido dessa doença comprida dele". Assim, vou arriscar referir-me às doenças em tela - diabetes mellitus e hipertensão arterial sistêmica - pela ideia de "comprida".

Nesse termo, há a ideia de "cronicidade" porque é uma experiência insistente e que demanda atenção constante; há a ideia de "longa duração" pelo tempo acumulado de sofrimento e cuidados; mas há também uma ideia de espaço, de distância, de lonjura. O "comprido" pode se referir ao tempo nas lembranças acumuladas desde as primeiras experiências de acomodação e cuidado com a doença até as projeções de planejamento de trabalho que se antevê pela frente. O "comprido" pode se referir ao espaço na ideia de um trajeto percorrido como sofredor e como cuidador, pelos corredores e burocracias hospitalares, pelos altares e encontros da igreja, pelas casas de parentes e vizinhos que ajudaram a acolher. A imagem de "comprido" me remete a uma rua muito longa que se trilhou desde que os primeiros sintomas foram sentidos e as primeiras mudanças foram percebidas. Mas essa rua continua para frente também, muitas vezes, a se perder de vista, sem a possibilidade de se ver seu fim. Como em uma rua, pode-se caminhar para trás, para frente ou ficar parado olhando ao redor. Não há necessariamente uma única direção correta, mas, de forma um pouco esperançosa, algo "comprido" geralmente termina em algum momento, em algum ponto. Depois de caminhar, indo e vindo por 
todo o espaço da "doença comprida", o tempo vai ter passado também e esse final pode ser esperado como cura ou descanso. Vale lembrar que a passagem de tempo e a mudança de espaço também são experiências muito significativas para pessoas que migraram em busca de dias melhores, como é o caso das que conheci no bairro da Guariroba e aqui serão apresentadas. A busca por uma outra cidade ou por um outro serviço de saúde parece recorrente entre elas.

As doenças compridas são também mais sofridas porque precisam conviver intensa e continuadamente com os serviços de saúde públicos e privados, com atendimentos de qualidade ou não. Em 2013, em um muro diante de minha casa, foi deixada uma mensagem na calada da noite e permanece até hoje ali. Em letras vermelhas, lia-se "Vandalismo é a fila do SUS". Inspirada por essa eloquente mensagem, decidi priorizar, para esse artigo, o que eu tenho ouvido de meus interlocutores ao enfrentarem as filas e desafios do SUS quando passam a cuidar de suas doenças compridas. Esse artigo pretende mostrar como é doloroso sentir esse tipo de vandalismo na própria pele todos os dias que, ademais, somado às dores próprias das patologias compridas. Aqui, priorizarei as vozes daqueles que utilizam os serviços do SUS, não necessariamente daqueles que realizam, oferecem e mediam os mesmos. Embora eu considere que a opinião dos profissionais de saúde sobre os serviços que eles próprios produzem (e, por vezes, utilizam) também seja parte integrante e igualmente relevante para compreendermos perspectivas críticas sobre o SUS (Fleischer, 2012; Fleischer, 2018), aqui atentarei para os "usuários" e para as experiências que acumulam, tentando conviver com suas doenças compridas, procurando serviços que possam lhes aliviar os sofrimentos.

\section{Os passos metodológicos}

De 2008 a 2015, perambulei intensamente pelo bairro da Guariroba, que fica localizado na Ceilândia, a maior cidade em termos populacionais do Distrito Federal. A Ceilândia fica na porção sudoeste do quadrilátero da capital, a 35km do seu centro e, nos dias de hoje, pode ser alcançada por carro, ônibus e metrô.

Conheci pessoas como Dona Marieta e seu esposo em diferentes espaços. Estive pelos corredores de espera, farmácia, sala de acolhimento, consultórios e grupos de apoio de um centro de saúde. Além disso, frequentei o grupo de 
ginástica do local, algumas igrejas e, sobretudo, as casas das pessoas. Em geral, optei por conversas informais, com ajuda de um roteiro de perguntas bastante flexível e adaptado a cada personagem e ao fluxo sugerido pelos diálogos. Raramente gravei em áudio ou filme, mas recorri ao caderno de campo, posteriormente reconstruído em diário de campo. Não foi uma prioridade investir na quantidade de entrevistados, mas numa módica rede de contatos, com uma expansão muito gradual e baseada nas indicações feitas pelos interlocutores dentre suas redes na família, na vizinhança e no grupo de ginástica (Fleischer e Batista, 2015). Ao longo desses anos, devo ter conhecido e conversado com cerca de 150 pessoas, aprofundando diálogos continuados e frequentes com cerca de três dezenas delas. Os sucessivos e específicos projetos de pesquisa foram submetidos e aprovados pelo referido comitê de ética em pesquisa de minha universidade.

Antes de começar a falar sobre a saúde, era comum perguntar um pouco sobre a trajetória de vida dessas pessoas, geralmente emigradas de estados do Nordeste brasileiro ou de Minas Gerais e Goiás. Chegaram aqui adolescentes ou jovens adultos para ajudar na construção da capital federal (Resende, 1985; Ribeiro, 2008; Tavares, 2011). Além disso, eu também queria saber da Guariroba, esse bairro da Ceilândia onde acabaram se instalando no espaço de uma grande fazenda que existia no local e que batizou o bairro. Nessa altura da conversa, era comum ouvir sobre o barro e a lama, já que as ruas ainda não estavam pavimentadas na década de 1970. Ou sobre a falta de água encanada para abastecer as casas. Como em qualquer conjunto habitacional popular (Costa, 1978; Borges, 2004; Cavalcanti, 2009), a urbanização chegou aos poucos, como resumiu Dona Dora (dona de casa, casada, duas filhas, goiana): "Tinha carência de muita coisa aqui”. Em meio às alusões infraestruturais, a dificuldade de acessar o sistema de saúde também foi considerada, conforme lembra a mesma senhora:

Não tinha farmácia. Se a gente precisava comprar algum remédio, a gente tinha que ir lá na farmácia da Ceilândia Sul, lá em cima. Ponto de ônibus também não tinha aqui. Quando a gente queria pegar condução tinha que ir para lá também. E comércio também era bem pouco. Telefone, então, deus me livre, que ninguém tinha telefone na época. Só tinha um orelhão e quando a gente precisava dar um telefonema, era uma fila que corria o risco dele não prestar. Que quase sempre tava com defeito ou alguém depredava. Aí, era sufoco. Posto [de saúde] não tinha, não. Hospital era Taguatinga, mas não tinha hospital de Ceilândia ainda não. Tỉnha não. Eu me lembro que quando eu precisava de emergência, eu só ia pra Taguatinga [cidade vizinha]. 
Ainda assim, umas das razões para migrar para o Distrito Federal nos anos 1960 e 1970, foi a procura por tratamentos médicos, pontuais ou continuados. Dona Miriam (dona de casa, viúva, 10 filhos, mineira) lembrou de como saíram do pequeno roçado que possuíam para tratar do marido, Seu Bóris: "A gente é de uma cidade chamada Aimorés. A gente veio porque o Bóris já estava doente. Ele tinha um problema de coluna e mais reumatismo. O irmão dele já morava pra cá e trouxe a gente para poder ver se cuidava do Bóris". Mesmo ainda em construção, a malha hospitalar do DF se apresentava como uma opção melhor do que aquelas deixadas nas cidades pequenas e dos estados vizinhos.

Aproveitando a experiência desses senhores e senhoras, na casa dos 60, 70 e 80 anos de idade (Fleischer e Batista, 2013), pelos espaços hospitalares do DF, desejo adensar as percepções sobre o funcionamento dessas instituições. Para tanto, trago três sentidos que emergem com força entre os dados: O "esperar" pelos serviços de saúde, o "ser atendido/a" pelos mesmos e, por fim, o "correr atrás" de soluções para suplantar as limitações encontradas nesses serviços. O objetivo, no presente artigo, é trazer uma mirada específica sobre os serviços de saúde: aquela que parte das pessoas que os procuram e utilizam com uma alta frequência, já que precisam resolver achaques relacionados às suas doenças compridas. Para tanto, elegi alguns trechos das conversas que empreendi com a expectativa de que possam ilustrar três formas bastante recorrentes de perceber e se relacionar com os serviços de saúde no DF. É possível que essa trinca de sentidos seja identificada nos demais centros de saúde da cidade, guardadas as especificidades de cada local.

Filio-me a boas etnografias que têm descrito os trânsitos e conhecimentos dos usuários ao percorrem os serviços de saúde (Nascimento, 2008; Giglio-Jacquemot, 2005). Contudo, julgo que o triplo pertencimento identificado entre essas pessoas - usuário, adoecido e crônico - possa oferecer alguma contribuição para (re)pensar os serviços de saúde. Beneficio-me também do acúmulo produzido, sobretudo pelas áreas da Saúde Coletiva, de atentar para o funcionamento dos serviços de atenção básica e inventar metodologias para conhecê-los e avaliá-los.

\section{Esperar}

Ainda que 40 anos tenham se passado desde as primeiras memórias de 
Dona Dora e Dona Miriam, era recorrente ouvir relatos pesarosos e queixosos sobre o que julgavam como uma precariedade persistente em relação aos serviços oferecidos no bairro nos dias de hoje, em especial, os centros de saúde. Desde 2008, quando por ali comecei a circular, a cidade contava com 12 unidades básicas de saúde e, ali nas imediações da Guariroba, havia três delas. Um dos aspectos muito mencionados se refere ao ritmo dos procedimentos.

Ali [em um desses dois centros de saúde do bairro] é assim: Você tem que esperar seis meses para uma consulta. Aí, você acaba se esquecendo e nem vai no dia que chega a consulta. Passou muito tempo e você se esquece. O exame, é um ano para sair o resultado. Quando você vai pegar o resultado e levar pro médico, não adianta mais porque passou muito tempo e você já tá diferente. Tem que fazer tudo de novo. Então, é bem difícil ali. (Dona Evelina, dona de casa, viúva, três filhos, mineira)

Dona Miriam, que ficou viúva em 2011, acompanhou os desdobramentos do AVC de Seu Bóris por muitos anos. Nossas conversas aconteceram antes do falecimento do esposo, quando os cuidados diários com o mesmo estavam num momento bastante intenso e cansativo. Ela acreditava que o centro de saúde vizinho pouco mudou nas últimas décadas e tinha opiniões semelhantes àquelas esboçadas por Dona Evelina no parágrafo anterior:

\begin{abstract}
Ah, minha filha, até hoje é ruim. Se você marca a consulta em dezembro, vai conseguir lá pra janeiro ou fevereiro. Mas quase que a gente não usa o Centro de saúde aí. Mas eu pego meu remédio da pressão. Quando o Bóris era bom, ele ia de madrugada fazer fila do lado de fora para conseguir marcar uma consulta. Mas vem muita gente do entorno, por isso fica cheio desse jeito. Faz fila na hora do almoço também. A consulta é difícil. Exame também é difícil. Por exemplo, para o Bóris, demoraram três anos para ligar e avisar da vaga. A minha mãe foi outro caso. Era um caso de urgência, mas demoraram três meses para marcar. Quando ligaram para cá, ela já tinha morrido, imagina só. Mas eu pego o medicamento no posto. Dão a receita. Mas para o cálcio, eu pego na Policlínica [em Taguatinga, cidade vizinha].
\end{abstract}

As pessoas mencionavam vários espaços hospitalares por onde circulavam no Distrito Federal. Elas explicavam que a demora de atendimento nos serviços, de forma geral, era o que as impulsionava para encontrar outras soluções para os problemas de saúde. Sugiro que, nessa circulação, além de, na maior parte das vezes, conseguirem algum encaminhamento, elas também angariavam um rol bastante complexo de experiências sobre o funcio- 
namento desses serviços. Esse rol lhes permitia direcionar mais especificamente cada tipo de problema e não precisar depender, exclusivamente, da instituição mais próxima de casa. Essas informações eram atualizadas a cada história contada e compartilhada por Dona Miriam, Dona Evelina e Dona Dora e suas vizinhas de bairro ou de corredores de espera nos hospitais.

No depoimento acima, Dona Miriam teceu duras críticas ao centro de saúde local, contando inclusive a triste história de sua mãe que morrera antes de a consulta conseguir ser marcada. Ainda assim, ela sabia que a receita médica e o medicamento correspondente para seu problema de pressão seguramente poderiam ser conseguidos nessa mesma unidade de saúde. Outro medicamento, para sua osteoporose, só era encontrado na cidade vizinha. Assim, ela dependia de uma busca fragmentada e desgastante por soluções, muitas vezes transitando por todo o território do DF. Ainda assim, um roteiro estratégico para usar os serviços de saúde vai sendo construído ao longo do tempo, especialmente quando se vive e/ou se cuida de uma doença comprida.

Aos poucos, eu ia entendendo outras nuances desse quadro. Havia uma tipologia de "usuários": Os pacientes comuns e os "pacientes de cartão", isto é, aqueles com as doenças de hipertensão arterial e/ ou diabetes mellitus. Estes últimos, ao se dirigirem ao balcão da UBS, seriam cadastrados e receberiam um cartão. Ao final da consulta do HIPERDIA, era nesse cartão que o profissional de saúde marcaria a próxima consulta. Era uma marcação "automática", como descreve abaixo, Dona Dora:

Aí, no posto, é assim: Eles já fazem o acompanhamento automático. Agora dia 26, eu tenho a consulta. Então, eles já marcam a outra. Duas vezes por ano. Então, já deixa marcado, entende? Corre até o risco de a gente esquecer, que é muito espaçada. Tem que sempre ficar olhando no cartão, se não, esquece.

Claramente, o sistema dava preferência ao paciente de cartão, visando fidealizá-lo ao serviço e evitando que tenha que enfrentar as filas ordinárias de marcação de consultas. Parece que, ao inventar a estratégia dos "cartões", a Secretaria de saúde reconhecia e naturalizava que as filas eram um problema.

De fato, essas consultas eram espaçadas, mas, caso o usuário conseguisse se lembrar delas e se apresentar ao centro de saúde na data marcada, elas seriam garantidas. Era muito diferente de uma consulta agen- 
dada para um paciente comum que abordasse o atendente do balcão, como Dona Miriam lembrou ter sido o caso do seu marido com AVC e da mãe que morreu sem atendimento. Dona Dora lembrou ainda que:

Esse cartão, ele já vem acoplado do outro cartão do remédio que a gente pega todo mês. É porque eu sou muito esquecida, muito esquecida. Então, eu boto sempre na gaveta ou na bolsa, que é local que eu sei que eu vou mexer sempre. Porque, do contrário, eu perco mesmo. Aí, como eu tenho que pegar o remédio todo mês, aí eu também olho a data da consulta.

Com o "cartão da consulta", essas pessoas tinham acesso a um ciclo de atividades: as aferições corporais, o grupo de apoio e o atendimento clínico. Com um segundo cartão, o "cartão do remédio", a cada mês, essas pessoas poderiam ir à farmácia do centro de saúde e tinham acesso direto aos medicamentos, utilizando a mesma receita recebida na primeira consulta. Só precisavam revisitar os médicos na consulta seguinte, dali a uns meses. Era proposital, portanto, que os dois cartões estivessem grampeados, para que a visita mensal por conta dos medicamentos lembrasse o paciente da visita clínica a cada tri ou quadrimestre, se diabético ou hipertenso, respectivamente.

Ainda assim, Dona Dora tinha razão: esse espaçamento das visitas era difícil de acompanhar ou memorizar. Era uma temporalidade institucional tentando conviver com outra, doméstica. O ritmo das doenças não correspondia ao ritmo dos serviços de saúde. Essa senhora me ensinava como era necessário criar artifícios - guardar os cartões em lugares na casa que sempre eram visitados - para que os dois ritmos - da casa/corpo/experiência e do centro de saúde/consulta/diagnóstico - se encontrassem e pudessem dialogar.

Aqui, percebo o esforço empreendido por essas pessoas para fazer sua diabetes ou hipertensão, às vezes sentidas diariamente, se adequar à disponibilidade oferecida pelo centro de saúde. Mesmo sem sintomas, também Dona Dora percebia que este convívio com o centro de saúde era positivo, mas “espaçado" demais. Talvez essas pessoas estivessem dizendo que para doenças compridas, com variações inesperadas e, por vezes, com "crises", dois ou três encontros por ano não eram a melhor maneira de oferecer cuidado e acompanhamento. Talvez um sistema de "portas abertas" ou de plantão fosse o ideal imaginado por essas pessoas.

Dona Evelina deu uma dica nesse sentido quando contou sobre um 
centro espírita que funcionava numa cidade do entorno do DF, em Santo Antônio do Descoberto. Sua sobrinha era caseira do lugar. Em uma ocasião, quando visitava a sobrinha, aproveitou para tentar solucionar um problema dermatológico que vinha sofrendo. Explicou como foi: "Lá tem um centro espírita e tem um médico que atende todo mundo que chega lá. Qualquer um que chega, ele atende. Ele atende todo mundo no sábado. Ele me passou outra pomada para as feridas". Esse modelo de "atender todo mundo que chega" poderia ser uma forma de contornar as "visitas muito espaçadas". "Chegar" queria dizer o próprio adoecido procurar o serviço e ser atendido quando julgasse necessário. "Marcar" queria dizer o adoecido esperar para ser atendido, mesmo que não estivesse mais com os sintomas quando a consulta finalmente chegasse. Ainda assim, as pessoas com crises medicadas fora do centro de saúde, como no caso de Dona Evelina, ou assintomáticas, como no caso do problema de pressão de Dona Dora, sabiam que precisavam comparecer à consulta marcada automaticamente porque essa assiduidade garantia o privilégio de continuar sendo uma "paciente de cartão". Se deixassem de ir duas vezes consecutivas, sabiam que seriam retiradas do programa do HIPERDIA e, mais grave do que isso, perderiam o acesso a todo o ciclo de consultas, aferições, medicamentos, informações, favores etc.

Percebo que as doenças compridas, como é o caso dos problemas de pressão e de diabetes, por exemplo, pareciam demandar mais do que a marcação preferencial, via os "cartões". Pareciam demandar um sistema de saúde que estivesse disponível para o ritmo dessas doenças "salientes", adjetivação comumente usada por essas pessoas. Ao que parece, a marcação preferencial, disponível aos "pacientes de cartão", era oferecida como uma grande dádiva pelos serviços de atenção básica (Machado, 2012). Mas não eram recebidos como dádiva suficiente para os casos de doenças que exigiam cuidado continuado. Talvez essas senhoras estivessem me sugerindo que, além dos cartões, um sistema preferencial para os momentos de crise e mal-estar fosse um serviço complementar e fundamental aos hipertensos e diabéticos. Pareciam me dizer que o atendimento estava excessivamente centrado nas consultas médicas e que todo o sistema funcionaria melhor se a sala de acolhimento, o grupo de apoio e a farmácia fossem ainda mais permeáveis, disponíveis e sensíveis às queixas apresentadas. As crises de pressão e de glicemia, constantemente mencionadas, não poderiam esperar o centro de saúde abrir, o balcão de atendimentos não ter fila 
ou a consulta acontecer dali a meses. Esperar tornava essas doenças ainda mais compridas e as temporalidades da experiência e dos serviços eram diferentes.

\section{Ser atendida}

Se, na seção anterior, apresentei relatos eopiniões sobre oque acontecia antes (esperarpelamarcação)edepois daconsulta (esperarpeloexame), nessaseção, trago passagenssobrequandoessas pessoaseram, finalmente, atendidas. Aqui, oscomentários sobre as consultas se referem, sobretudo, à relação com os profissionais e os medicamentos prescritos. Os comentários críticos se dirigiam ao encontro clínico.

A Dra. Fernanda não nos dá tempo de a gente dizer a queixa da gente, dizer o que a gente tá sentindo. Ela não ouve a gente. Já o Dr. Josué é paciente, ouve a gente com calma. Ele fala os resultados. Fala o resultado dos exames para a gente. Se eu não entendo, porque eu sou meio mouca, ele repete, explica de novo. (Dona Jandira, dona de casa, casada, cinco filhos, baiana)

Dra. Fernanda era grossa. Nem perguntava o que a gente tinha. Uma vez trouxe meu menino com dor de ouvido. Ela não deixou ele falar. Baixou a cabeça e foi escrevendo o remédio. Mas sou eu que sinto a dor, eu sei onde dói, não é? O Dr. Josué eu gosto. É muito bonzinho. Um dia eu estava com infecção urinária. Ele pediu para eu fazer os exames e trazer no dia seguinte, que eu não precisava entrar na fila nem marcar de novo. Eu fiz e ele me atendeu mesmo. (Dona Leila, casada, um filho, dona de uma banca de verduras na CEASA, piauiense)

Uma "boa consulta", pelo que entendi, acontecia porque havia um "bom médico" do outro lado da mesa ou da maca. Um "bom médico", como tantas vezes ouvi, "olha nos olhos da gente", "deixa a gente falar", "escuta a gente" e "explica tudo com calma". Esse bom profissional explicita em seu trato com o usuário o reconhecimento, pelo olhar e pela escuta (Bonet, 2004), de que, primeiro, ali havia uma pessoa com uma história a contar e, segundo, de que a história, contada na forma das queixas, era legítima e relevante. Esse reconhecimento era exibido de várias maneiras, no momento em que o usuário entrasse na sala, se sentasse e fosse estimulado a falar, durante a narração etiológica sem interrupções, ao mirar o interlocutor, ao tomar notas do que fosse dito, etc. (Calvo-Gonzalez, 2011). O reconhecimento era fundamental para instituir um atendimento relacional, pelo visto, muito valorizado pelos nossos interlocutores (Ferreira, 2005).

O "bom médico" foi contrastado com um " mau médico", nas falas de Dona Jandira e Dona Leila, acima. Nesse centro de saúde, o Dr. Josué 
era muito mencionado como o exemplo positivo, em franco contraste com a Dra. Fernanda. Há um trecho da fala de Dona Jandira que, embora singelo, guardou potencial sintético: "O Dr. Josué é paciente, ouve a gente com calma". De fato, me encanta a ideia de um "médico paciente", numa clara inversão de papeis convencionalmente esperados para o encontro clínico. $O$ "médico paciente" era aquele que fazia o papel do usuário, de esperar, ouvir, procurar entender. Poderíamos imaginar o polo complementar dessa inversão: um "paciente médico" ou, ao menos, um "paciente ativo", com a autoridade de explicar a própria experiência da doença, de narrar e contar o que havia percebido e o que julgasse ser necessário fazer, como disse Dona Leila nesse sentido: "Mas sou eu que sinto a dor, eu sei onde dói, não é?".

Foi fácil identificar a falta de reconhecimento também em outros aspectos do encontro clínico. A troça, a rapidez do encontro, os comentários pouco acolhedores:

Eu tenho um problema de ouvido. Sabe o que a Dra. Fernanda falou para mim? "Olha, esse seu problema aí só vai curar depois que o senhor nascer de novo". Que ela quer dizer com isso? Quando eu morrer, né? Isso é coisa que se fale para paciente? (Seu Bastos, pedreiro aposentado, esposo de Dona Jandira, cinco filhos, baiano)

Outro dia, sabe o que aconteceu? Eu e o Bastos fomos lá. Ele tinha consulta. Aí, a médica pediu para eu ir ali na secretaria para pegar os exames. Foi o tempo de eu ir lá e voltar, ela já tinha liberado ele! Imagina, poucos minutos! Ainda bem que ela é médica do Bastos e não minha. (Dona Jandira)

Ele me olhou e disse assim, "Olha, o seu pâncreas, ele não serve mais para nada. Se você pudesse, eu já sugeriria para você providenciar um caixão. Aí, coloca o pâncreas no caixão e pode jogar fora". Foi assim mesmo que o Dr. Eduardo falou para mim, imagina. (Dona Renata, babá aposentada, solteira, piauiense)

A intensa frequência pelos consultórios do centro de saúde, proporcionada pela doença comprida, permitia que esses adoecidos conhecessem todos os profissionais do centro de saúde. Era inevitável que os parâmetros de bons médicos - e também boas enfermeiras, farmacêuticos, laboratoristas, nutricionistas, atendentes de balcão - fossem construídos em depoimentos comparativos, como vimos acima. O "sistema de cartão" facultava mais acesso à instituição, isto é, a muitos funcionários e suas diferentes formas de atender e tratar.

Depois da consulta, já em casa, ao serem perguntados sobre os serviços de 
saúde, os interlocutores também contavam sobre os efeitos dos medicamentos. As críticas feitas por essas pessoas até aqui, em relação à demora por atendimentos, consultas e exames e também à forma como eram tratados pelos profissionais, pareciam culminar nos tratamentos ineficientes. $\mathrm{O}$ "remédio fraco" era uma alusão recorrente nesse sentido. Era como se tudo fosse um pouco "fraco" nos serviços prestados e os efeitos do princípio ativo do medicamento simbolizassem isso:

Agora, esse remédio lá do posto de saúde não vale muito pra mim, não. Esse Captromed, o $25[\mathrm{mg}]$ não adianta. Tomo dois e não adianta. Eu compro porque eu acho que o do posto não faz efeito. Não adianta mesmo, se eu continuar tomando só esse aí do posto, a pressão altera e altera mesmo. Fica queimando a orelha, dá dor de cabeça. (Dona Corina, dona de casa, viúva, seis filhos, mineira)

Hoje, eu sou hipertensa, sabe. Tomo um comprimido uma vez por dia. Quando ela não baixa, eu tomo três comprimidos por dia. Eu tomava o remédio do posto, mas não baixava a minha pressão. Depois, eu acabei indo em outro médico. Depois, eu fui num cardiologista particular e ele falou que os remédios do centro são mais fracos. O que vem pro posto é só do fraco. Ele me deu uma receita para comprar a preço de custo na Drogaria Renata porque é mais forte. (Dona Madalena, ambulante aposentada, viúva, três filhos, mineira)

Por vezes, a automedicação resolvia essa fraqueza do fármaco e as doses eram multiplicadas por conta própria. Outras vezes, devolviam-se os medicamentos no postinho, direcionando reclamações ao dispensador. Em alguns casos, esta reclamação era feita diretamente ao prescritor, numa consulta de retorno ou mesmo numa nova consulta, marcada especificamente para esse fim, como lembrou Dona Cirlene:

Eu tomo o remédio todo dia. Eu tomava Metildopa, mas eu ficava dormindo demais. Dormia toda hora. Eu falei isso para o médico. Eu não estava gostando disso, não. O médico me passou outro, que eu esqueci o nome agora... Depois, me passou outro, o Atenolol $50 \mathrm{mg}$. Eu tomo um de manhã. Pego do governo, esse. (Dona de casa, viúva, três filhos, boliviana)

Interpelar o sistema de saúde, seja seguindo uma via alternativa e autônoma como na automedicação, seja com os funcionários mais acessíveis do baixo escalão (como na farmácia ou na portaria) ou com aqueles identificados como principais responsáveis por um remédio fraco ou perigoso (os médicos), poderia garantir algumas soluções. Dona Corina tentou ajustar sua dose. Dona Madalena procurou o serviço privado, tido como mais confiável. Dona Cirlene 
conseguiu, do médico que lhe prescrevera o primeiro remédio, um segundo mais adequado ao bem-estar e/ou ao bolso.

Assim, a avalição sobre os serviços de saúde começava muito antes de entrar em contato direto com os mesmos e continuava muito tempo depois de ter saído de suas salas, portas e cercas. A avaliação dos serviços era contínua, como também a convivência com as doenças compridas. Era uma relação comprida, poderia dizer. Abordavam, demandavam, esperavam, recebiam serviços, tomavam remédios e, acima de tudo, comentavam sobre tudo isso com os colegas de grupo da hipertensão ou as vizinhas que também tinham a pressão alterada. Iam construindo, muito ativamente, um rol personalizado e comparativo dos centros de saúde, seus profissionais e medicamentos (Ferreira e Espírito Santo, 2012).

\section{Correr atrás}

Esperar pela marcação das consultas ou pelos resultados dos exames era uma queixa recorrente. Depois, esperar pelos corredores pelo atendimento, seja no dia da consulta marcada ou da consulta de cartão, também era fruto de críticas. Para tentar driblar a diferença entre o ritmo dos serviços e o dos padecimentos, ouvi muitas alusões às costuras entre o SUS público e privado:

Hospital público é muita dificuldade, sabe. São seis meses para marcar uma consulta. Ela [esposa com $\mathrm{AVC}$ ] está viva porque não usa o público. Se tivesse que esperar, já não tinha aguentado. (Seu Prudêncio, agente de serviços legislativos aposentado, casado, 9 filhos, baiano)

A gente correu atrás e mandou fazer os exames do Bastos no particular. Foi bastante dinheiro, mas a gente conseguiu, no final das contas. Mas agora a gente está esperando a consulta. Isso é que está demorando. Eu já até fui lá [no centro de saúde] de novo, ver se conseguia adiantar a consulta. Mas nada. (...) Eu vou toda semana lá naquele HRC [Hospital Regional da Ceilândia] tentar ver se a consulta dele foi marcada. Ele já fez todos os exames. Fizemos tudo no particular. E até agora nada de consulta. A gente não sabe mais o que fazer (Dona Jandira)

Eu tive muito problema de anemia. Passei 20 anos com anemia. Dos 31 até os 51. Eu tô com 51 anos agora. No ano passado, eu fiz um convênio, porque eu tava precisando de um médico. Meu ferro chegou a 8 no ano passado. O normal é 40, só para vocês terem uma ideia. O médico passou o Noripurum e o Combiron. Eu tomei tudo. Aí, o médico me mandou para um hematologista. 
Eu tomei 20 ampolas de intravenoso. Era um negócio preto, preto. Era quase um sangue, assim. Mas o meu convênio é fraco. Então, eu tomei só três ampolas no hospital que era da Unimed, o ex-Unimed. Hoje, chama Hospital Alvorada. (Dona Cirlene)

A esposa de Seu Prudêncio era hipertensa e, depois de ter sofrido um aneurisma, mantinha-se acamada havia alguns anos. O marido de Dona Jandira tinha DPOC e vinha com dificuldades para aceitar serviço de pedreiro dado à falta de fôlego. Dona Cirlene era uma senhora boliviana e viúva. Embora o filho e a nora morassem na "casa dos fundos" de seu quintal, era ela quem parecia ter que cuidar das várias doenças que lhe acometiam.

A expectativa dos três narradores era encontrar atalhos para acelerar o ritmo dos serviços. Seu Prudêncio tinha um bom plano de saúde e uma aposentadoria acima da média do bairro. Ainda assim, estava tentando um laudo médico para isentar a esposa do imposto de renda (afinal, como ele me disse, "uma pessoa paralítica não pode ficar pagando imposto"), retirava alguns dos medicamentos gratuitamente do centro de saúde e comprava a maior parte nas farmácias privadas do bairro, que lhe avisavam, inclusive, sobre promoções. A opção privatista era eficaz no caso do seu cuidado com a esposa, mas não deixava de contar com incursões pelos espaços públicos.

Como Seu Prudêncio, Dona Jandira também mostrou que, para atenuar os efeitos das longas esperas, era preciso "correr atrás". Porém, nem sempre os atalhos eram exitosos. Por vezes, conseguiam realizar os exames "por fora", como diziam, mas a consulta, "por dentro", tardava. Ou vice-versa, como Dona Cirlene mostrou, o convênio havia permitido que encontrasse rapidamente um médico, mas não que seguisse por inteiro o tratamento prescrito. A alusão geral era de que os serviços privados eram sempre mais céleres do que os públicos. O desejo parecia ser de se autonomizar de uma vez dos públicos, mas a renda não permitia que contassem exclusivamente com planos de saúde, laboratórios e clínicas privadas. E, mesmo assim, havia uma gradação na esfera privada que compreendia também os "convênios fortes" e os "convênios fracos".

Essas pessoas sempre me contavam das inúmeras estratégias para "correr atrás" e garantir ao menos um alinhavo, mais ou menos direto, mais ou menos oficial entre os serviços públicos e privados. As visitas aos hospitais eram apro- 
veitadas para resolver vários assuntos. Numa das minhas conversas de banco de espera, no início do mês de dezembro de 2011, conheci Dona Leila, que citei em seção anterior. Ela aguardava a consulta do clínico geral. Era sua consulta de cartão, no acompanhamento da diabetes. Mas ela me explicou: "Eu estou aqui com outros exames de vista, para mostrar ao Dr. Josué. Vou aproveitar a consulta para falar de outras coisas também”. Depois, vendo que a demora não seria pouca, pediu licença. Levantou e foi até a janelinha da sala de exames. Em alguns minutos voltou com um enorme sorriso em seu rosto: "Acho que vou jogar na loto hoje! O que você acha? Fui ali e consegui marcar uma intravaginal e também uma mamografia, tudo de uma vez! E para esse mês ainda, veja só! É difícil demais conseguir a consulta e os exames, nossa mãe!’.

Passei algum tempo dentro da farmácia deste centro de saúde. Observei como Fagundes, o farmacêutico, tratava vários dos usuários pelo nome, além de perguntar pela saúde e tratamento de outros membros da família. Quando perguntei sobre sua relação com o bairro, ele contou:

\footnotetext{
Sim, há pessoas que frequentam o posto há muito tempo já. Uma vez, uma senhora veio aqui e me deu uma camiseta de presente. Assim, a lei proíbe quando é dinheiro. O servidor público não pode aceitar. Mas quando é um agrado, tudo bem. Outro veio e me trouxe uma caixa de uva Niágara. Ela estalava na boca, de tão boa. Eu falei, "Não precisa, estou aqui para servir e tudo". Mas as pessoas ficam felizes quando são bem tratadas, querem retribuir.
}

Aproveitei para lhe perguntar se, geralmente, quem presenteava eram os pacientes de cartão: "Isso mesmo, nos dois casos - uva e camiseta - eram hipertensos". Fiquei curiosa sobre o presente em dinheiro que ele havia mencionado.

Isso já aconteceu. Uma vez, um cara veio bem cedo e conseguiu ser atendido. Ele ficou todo agradecido, todo feliz. No final, me chamou do lado de fora e disse, "Eu queria agradecer. Toma um trocado para você". Eu falei, "Você está me desacatando. Não posso aceitar isso. Eu trabalho aqui para todo mundo que procura o posto". Eu me senti ofendido, sabe.

O raciocínio de Fagundes me ajuda a pensar que nem todas as opiniões sobre os serviços de saúde são negativas e que as pessoas facilmente reconheciam e ficavam satisfeitas de poder usufruir de um bom serviço. Assim como Seu Prudêncio que nos contou que os seus conhecidos nas farmácias lhe telefonavam para avisar das promoções que poderiam lhe interessar. Seria estra- 
tégico também manter azeitadas relações semelhantes nos serviços públicos, como pode nos dar a entender o fato de se tentar presentear o farmacêutico do centro de saúde. Os contatos, nos espaços públicos ou privados, ajudavam a fazer o que, provisoriamente, chamo de rol ou de uma coleção particular de experiências hospitalares. Essa coleção precisava estar sempre ativa, atualizada e eficaz. A coleção não se abastecia somente de informações, portas ou números de telefones corretos, mas dependia muito do conhecimento sobre o funcionário, seu posto de trabalho, sua influência na instituição, seu jeito de atender, sua postura ética, etc. Rapidamente, Fagundes me fazia entender que, sim, era possível aceitar elogios, agrados e retribuições, mas nunca na forma pecuniária. Ele seguia o que a lei do funcionalismo público preconizava; mas, talvez, com outros funcionários, um trocado ajudasse a manter portas e serviços abertos. Uma coleção diversa e, principalmente, minuciosa seria o resultado concreto de quem tivesse "corrido atrás" de forma eficiente. E isso implicava, por exemplo, saber a que horas o balcão de exames estaria aberto, que clínicas particulares cobravam mais barato por um hemograma, que farmácias aferiam a pressão arterial gratuitamente ou que funcionários aceitariam um agrado para acelerar serviços, num intuito discreto em privatizar os serviços públicos.

As pessoas que entrevistei não se resignavam a cumprir apenas o que lhes era programado pelos serviços. Ter acesso ao espaço hospitalar era uma oportunidade para conhecer novos corredores, cartazes com avisos, nomes dos funcionários de outros setores. Era como se cada visita pudesse render mais um fragmento informacional para a "coleção". Esse fragmento, mesmo inútil naquele momento, poderia se revelar útil mais à frente, diante de outro problema de saúde, da família ou da vizinhança, por exemplo. Ou até esse fragmento poderia servir para encaminhar problemas antigos, que viessem se acumulando, sem encontrar espaço de escuta e resolução.

Sugiro, sobretudo, que a alta frequência dessas pessoas nos centros de saúde e hospitais se dava, muitas vezes, por conta das atividades de cuidado com as doenças compridas. Dona Dora, Dona Miriam, Dona Jandira, Dona Madalena, Dona Cirlene, Dona Filó e Dona Leila eram todas pacientes de hipertensão. Dona Renata e Dona Corina tinham diabetes. Os cônjuges de Dona Marieta, Dona Miriam, Dona Jandira e Seu Prudêncio sofriam de derrames e asma. Eram 
todos motivos que os levavam ao postinho toda semana ou, ao menos, todo mês. Estar ali assiduamente lhes permitia conhecer melhor esses espaços e usufruir de novas oportunidades para si e para os seus. As doenças eram compridas, mas as "coleções particulares de experiências hospitalares" também se esmeravam em ser. De modo semelhante ao que Nascimento (2008) notou entre os casais que arduamente buscavam soluções para suas limitações reprodutivas em Porto Alegre/RS, as dificuldades encontradas nestes serviços da Ceilândia e Distrito Federal - sobretudo o tempo transcorrido aí dentro - eram mote para se refletir sobre o caminho percorrido e, por tabela, também sobre a doença vivenciada.

\section{Considerações finais}

Aqui, talvez eu tenha colocado tinta excessiva na responsabilização individual pelos problemas dos serviços de saúde, como se a consulta ruim se devesse somente à médica que não olha nos olhos do paciente ou a demora em marcar um exame fosse unicamente devido à displicência do atendente. Centrar-nos nos depoimentos das pessoas que convivem com as doenças compridas talvez nos faça escapar de um quadro mais geral e estrutural. Como em qualquer outro estado brasileiro, o SUS no Distrito Federal sofre de problemas de política pública, de gestão, de financiamento, de logística, de desmonte deliberado, etc. Mas gostaria que esses relatos seguissem marcando a memória, como exemplos vívidos e capazes de também serem uma forma de nos manter comprometidos com a melhora dos serviços de saúde.

Creio que é preciso qualificar as queixas contra o SUS, que sempre ouvi pelos corredores e casas que frequentei como etnógrafa. É preciso levar a sério essas queixas bem como o conhecimento que as pessoas acumulam ao circularem penitentemente por essas instituições. Sugiro que levemos tão a sério quanto as concepções de corpo e doença que vamos buscar ou as representações sociais sobre o uso de medicamentos ou as práticas tradicionais de cuidado. A história de uma migrante idosa pelo SUS da Ceilândia pode ser semelhante e complementar a outras histórias relatadas por senhoras e senhores Brasil afora. É possível construir um quadro mais orgânico dessas percepções, para que funcione como um diagnóstico popular da saúde institucional do SUS.

Além disso, é possível que estejamos testemunhando um fermentar, ainda 
que individualmente vivido e comunicado, de um processo de construção de cidadania ao entrar em contato com tanta frequência e frustração com as franjas do Estado brasileiro. Esse fermentar pode eclodir na forma de reclamações in/formais, abertura de processos na ouvidoria da SES/GDF ou no Ministério Público Federal, na organização de associações de adoecidos, na compra de serviços privados de saúde, nas entrevistas concedidas a jornalistas e antropólogos, nas brigas e agressões aos funcionários das portarias ou balcões de atendimento. Por fim, esse fermentar pode estar se anunciando nas explosões de raiva e impotência que vemos em campo, nas reportagens de televisão ou nas imagens grafitadas pelos pontos de ônibus e muros da cidade e, sugiro, verbalizam um enorme cansaço diante do sofrimento comprido causado pelos serviços públicos, dentre eles, os de saúde.

Eu me propus, aqui, a enfrentar uma antropologia parcial. Ao considerar as queixas dos moradores de um bairro do DF sobre os serviços de saúde de sua região como, de fato, avaliações legítimas, o resultado pode parecer uma denúncia ou uma simples reprodução de suas opiniões. Espero, contudo, que o texto tenha oferecido mais do que isso ao organizar - na forma do esperar, ser atendido e correr atrás - os diagnósticos elaborados sobre o SUS por essas pessoas da Guariroba. Almejo também ter mostrado que, além de avaliações, havia ações concretas realizadas por essas pessoas, como observar, perguntar, comparar, reunir e circular informações, por exemplo. Nesse momento, depois de tantos anos convivendo e encontrando com essas mesmas pessoas e ouvindo seus relatos de sofrimentos patológicos e institucionais, julgo pertinente vocalizar essas queixas e trazer o que considero um belo e localizado exemplo para a potente mensagem que foi deixada no muro perto de minha casa.

\section{Referências}

BONET, Octavio. Saber e sentir. uma etnografia da aprendizagem da biomedicina. Rio de Janeiro: Editora Fiocruz, 2004.

BORGES, Antonádia. Tempo de Brasilia: etnografando lugares-eventos da política. Rio de Janeiro: Relume Dumará, 2004.

CALVO-GONZALEZ, Elena. Construindo corpos nas consultas médicas: 
uma etnografia sobre Hipertensão Arterial em Salvador, Bahia. Caderno CRH, Salvador, v. 24, n. 61, p. 81-96, 2011.

CANESQUI, Ana Maria. Olhares socioantropológicos sobre os adoecidos crônicos. São Paulo: HUCITEC/FAPESP, 2007.

CAVALCANTI, Mariana. Do Barraco à Casa: tempo, espaço e valor(es) em uma favela consolidada. Revista Brasileira de Ciências Sociais, 24: 69-80, 2009.

COSTA, Ana Maria. Riqueza de Pobre: um estudo em antropologia da saúde. Dissertação (Mestrado em Antropologia Social), Programa de Pós-Graduação em Antropologia Social, Universidade de Brasília, Brasília, 1978.

FERREIRA, Jaqueline. O Programa de Humanização da Saúde: dilemas entre o relacional e o técnico. Saúde e Sociedade, v. 14, n.3, p. 111-118, 2005.

FERREIRA, Jaqueline e ESPIRITO SANTO, Wanda. Os percursos da cura: abordagem antropológica sobre os itinerários terapêuticos dos moradores do complexo de favelas de Manguinhos, Rio de Janeiro. Physis, 22(1), 2012, pp. 179198.

FLEISCHER, Soraya. O mundo dos bem e mal passares: vivendo com hipertensão arterial na Guariroba, Ceilândia/DF. Política \& Trabalho, João Pessoa, 37: p. 149-164, 2012.

. Descontrolada: uma etnografia sobre os problemas de pressão. São Carlos: EdUFSCar, 2018, no prelo.

FLEISCHER, Soraya e BATISTA, Jéssica Monique. "Isso aqui é a minha valência": notas etnográficas sobre um grupo de ginástica na Guariroba, Ceilândia, DF. In: FERREIRA, Jaqueline; FLEISCHER, Soraya. (Orgs.). Etnografias em serviços de saúde. Rio de Janeiro: Garamond, 2015, pp. 209-242.

O tempo da falta e o tempo da bonança: Notas sobre experiências de cronicidade na Guariroba, Ceilândia/DF. Anuário Antropológico, 2012, Brasília, 195-224, 2013.

GIGLIO-JACQUEMOT, Armelle. Urgências e emergências em saúde: perspectivas de profissionais e usuários. Rio de Janeiro: Editora Fiocruz, 2005.

MACHADO, Lia Zanotta. Entre o inferno e o paraíso. Saúde, direitos e confli- 
tualidades. Série Antropologia, 342. Brasília, 2003.

NASCIMENTO, Pedro Francisco Guedes do. Reprodução, Desigualdade e Políticas Públicas de Saúde: uma etnografia da construção do desejo de filhos. Tese (Doutorado em Antropologia Social), Programa de Pós-Graduação em Antropologia Social, Universidade Federal do Rio Grande do Sul, Porto Alegre, 2009. PARSONS, Talcott. The social system. London: Routledge \& Kegan Paul, 1951. RESENDE, M. L. S. Ceilândia em movimento. Dissertação (Mestrado em Sociologia), Programa de Pós-Graduação em Sociologia, Universidade de Brasília, Brasília, 1985.

RIBEIRO, Gustavo Lins. O capital da esperança: a experiência dos trabalhadores na construção de Brasília. Brasília: EdUnB, 2004.

TAVARES, Breitner. Na quebrada, a parceria é mais forte: jovens, vínculos afetivos e reconhecimento na periferia. São Paulo/Brasília: Annablume/Fundo de Apoio a Cultura do Distrito Federal, 2012. 


\title{
How can long diseases teach us about the health services?
}

\begin{abstract}
Recently, on a wall close to my home, a graffiti was left during the night. In red paint, it was read "Vandalism is the SUS line". Inspired by this strong message, I decided to prioritize, for this article, what I have heard from my interlocutors when facing the lines and challenges to use the SUS program. This article intends to show how painful it is to personally feel this vandalism every day, as well as the pains produced by long diseases, as chronic diseases have been called in the neighborhood of Guariroba (Ceilândia/DF). The idea is to note the perceptions related to the way the local health institutions work in the city. In this way, I suggest three concepts that strongly emerge from the data: "Waiting" for the services, "be attended" by the health professionals and individually and/ or collectively "go after" solutions to overcome the limitations in the services. Something specific is accumulated by the experience of a long disease in order to face the daily vandalism offered by SUS.
\end{abstract}

Keywords: Chronicity; Health services; Primary attention.

Recebido em 12 de abril de 2017. Aceito em 25 de fevereiro de 2018. 